\title{
Clinical outcomes of endovascular treatment for chronic aortic occlusion: a retrospective multicentre registry
}

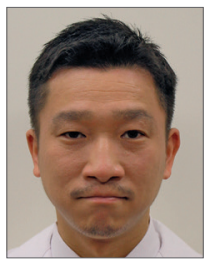

Taku Kato ${ }^{1 *}$, MD; Kan Zen², MD; Osami Kawarada3 ${ }^{3}$ MD; Koji Hozawa ${ }^{4}$, MD; Hitoshi Anzai ${ }^{5}$, MD; Hiroaki Nakamura ${ }^{6}$, MD; Atsushi Funatsu7, MD; Daizo Kawasaki ${ }^{7}$, MD; Yoshinori Tsubakimoto ${ }^{9}$, MD; Akihiro Higashimori ${ }^{10}$, MD; Amane Kozuki ${ }^{11}$, MD; Satoaki Matoba ${ }^{2}$ MD

1. Department of Cardiology, Rakuwakai Otowa Hospital, Kyoto, Japan; 2. Department of Cardiovascular Medicine, Kyoto Prefectural University of Medicine, Kyoto, Japan; 3. Department of Cardiovascular Medicine, Ikuwakai Memorial Hospital, Osaka, Japan; 4. Department of Cardiology, Interventional Cardiology Unit, New Tokyo Hospital, Matsudo, Japan; 5. Department of Cardiology, Ota Memorial Hospital, Ota, Japan; 6. Department of Cardiology, Kakogawa Central City Hospital, Kakogawa, Japan; 7. Cardiovascular Center, Kyoto Katsura Hospital, Kyoto, Japan; 8. Cardiovascular Division, Department of Internal Medicine, Morinomiya Hospital, Osaka, Japan; 9. Department of Cardiology, Kyoto Second Red Cross Hospital, Kyoto, Japan; 10. Department of Cardiology, Kishiwada Tokusukai Hospital, Kishiwada, Japan; 11. Department of Cardiology, Osaka Saiseikai Nakatsu Hospital, Osaka, Japan

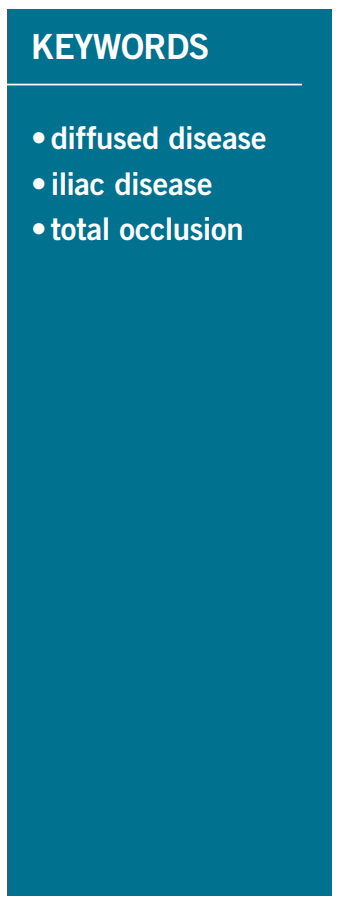

\section{Abstract}

Aims: The aim of this study was to evaluate the clinical outcomes of endovascular treatment (EVT) for chronic aortic occlusion (CAO) using multicentre registry data.

Methods and results: From April 2003 to December 2015, data on 73 consecutive patients (55 men and 18 women; aged $70.7 \pm 12.2$ years) who underwent EVT for CAO were collected retrospectively from 15 centres in Japan. The primary endpoint was the primary patency at 12 months after EVT. Secondary endpoints were procedural success and periprocedural complication rates. We analysed 67 patients who underwent complete endovascular revascularisation after 2007. Initial procedural success was achieved in 63 cases $(94.0 \%)$. Complications occurred in three patients (4.5\%) (stroke, $\mathrm{n}=1$; distal embolism, $\mathrm{n}=1$; accesssite haematoma requiring blood transfusion, $n=1)$. In patients after successful EVT $(n=63)$, the primary and secondary patency rates at 12 months were $90.7 \%$ and $97.7 \%$, respectively. During a mean follow-up period of 17.8 months, restenosis/re-occlusion was observed in eight patients $(12.7 \%)$.

Conclusions: EVT for CAO could be performed safely with a high procedural success rate. The short-term clinical outcome was acceptable despite lesion complexity.

*Corresponding author: Department of Cardiology, Rakuwakai Otowa Hospital, 2 Otowachinji-cho, Yamashina-ku, Kyoto, 607-8062, Japan.E-mail:Tak.Katoh@gmail.com 


\section{Abbreviations}

ABI

ankle-brachial index

CAD

CAO

CKD

COPD

CTO

CVD

EVT

IVUS

TASC

TLR

\section{Introduction}

Although favourable results of endovascular treatment (EVT) for aortoiliac lesions have been reported ${ }^{1-3}$, EVT for complex lesions, especially chronic total occlusion (CTO), still remains challenging ${ }^{3}$.

Chronic aortic occlusion (CAO) is defined as CTO of the infrarenal aorta with or without iliac artery occlusion; the specific ischaemic symptoms of CAO are commonly known as Leriche syndrome ${ }^{4}$. Surgical revascularisation has been the treatment of choice for patients with this disease. Only a small number of single-centre studies or single case reports have been published on the outcomes of EVT for CAO ${ }^{5-9}$. The purpose of this study was to evaluate the clinical outcomes of EVT for CAO using multicentre registry data.

\section{Methods \\ STUDY DESIGN AND PATIENT POPULATION}

This was a multicentre, retrospective observational study that included 73 Japanese patients (55 men, 18 women), who had a mean $\pm \mathrm{SD}$ age of $70.7 \pm 12.2$ years (range, $34-90$ years). The study was conducted in accordance with the Declaration of Helsinki and was approved by the ethics committee of each participating hospital. Patients had CTO of the infrarenal aorta, and EVT was attempted between April 2003 and December 2015 at 15 Japanese medical institutions. Anonymised data were collected and analysed.

Treatment indications and strategies were decided at the physician's discretion at each institution. We excluded two patients who underwent hybrid therapy (unilateral revascularisation and femorofemoral bypass) and three patients who underwent unilateral revascularisation. Furthermore, we excluded the first of the remaining 68 patients who underwent complete EVT. The patient had been treated in 2003, and there were major restrictions on the devices and techniques available in Japan at that time. The second and subsequent procedures had been performed annually since 2007, four years after the first case.

\section{EVT PROCEDURE}

The cardiologists at each hospital decided on the procedural strategies. Therefore, treatment strategies were not unified in each institution. Here, we describe one of the EVT procedures for CAO (Figure 1)9. Three sheaths were inserted from the bilateral femoral arteries and the left brachial artery under local anaesthesia.

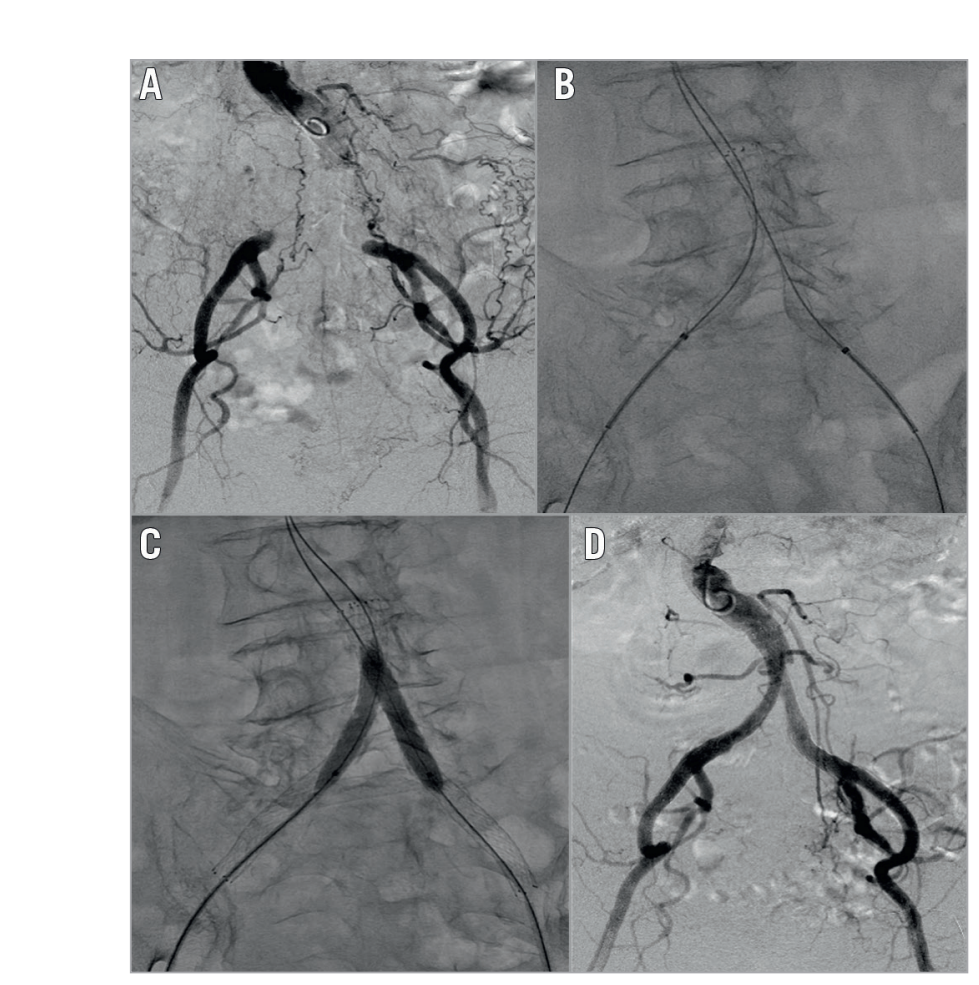

Figure 1. One of the interventional procedures. A) Preprocedural angiography showed total occlusion of the terminal abdominal aorta and bilateral common iliac artery. B) Kissing stent with self-expanding nitinol stents after guidewire crossing. C) Post balloon dilatation.

D) Postoperative angiography showed a favourable flow. 
Guidewire manipulation was performed intraluminally with a 0.014-inch guidewire. After the guidewire had successfully passed through the bilateral occlusive lesions, kissing stenting with two self-expanding nitinol stents followed by post-dilatation was performed.

\section{STUDY OUTCOMES}

Study outcomes comprised procedural success, procedural safety, and patency. The primary endpoint was primary patency at 12 months after EVT. Secondary endpoints were procedural success and periprocedural complication rates. Initial success was defined as $<30 \%$ residual stenosis without any flow limitation noted on the final angiography. A procedural complication was defined as any adverse event caused by endovascular treatment including death, stroke, emergent surgery, blue toe syndrome/distal emboli, vessel rupture, access-site complication with prolongation of the in-hospital stay, blood transfusion, gastrointestinal haemorrhage, worsening renal function (a 50\% increase in serum creatinine), and other critical complications.

\section{DEFINITIONS}

Primary patency was defined as the treated vessel without restenosis and repeat revascularisation that remained patent. Secondary patency was defined as patency achieved after reintervention for restenosis or re-occlusion of the treated vessel. Restenosis was defined as $>2.4$ peak systolic velocity ratio on duplex, $>50 \%$ stenosis on angiography or computed tomography. Coronary artery disease (CAD) was defined as angina with documented CAD, previous myocardial infarction, a history of percutaneous coronary intervention, and history of coronary artery bypass graft surgery. Cerebrovascular disease (CVD) was defined as a history of stroke or transient ischaemic attack, carotid artery stenosis of $>80 \%$, history of carotid artery stenting, or history of carotid endarterectomy. Chronic obstructive pulmonary disease (COPD) was defined as patients with a forced expiratory volume in $1 \mathrm{~s}$ (FEV1) of $<70 \%$ or COPD diagnosis requiring medical treatment. Chronic kidney disease (CKD) was defined as an estimated glomerular filtration rate (eGFR) less than $60 \mathrm{~mL} / \mathrm{min} / 1.73 \mathrm{~m}^{2}$.

\section{STATISTICAL ANALYSIS}

Results are expressed as the mean \pm standard deviation or numbers with percentages. Statistical analyses were performed using EZR (Saitama Medical Center, Jichi Medical University, Saitama, Japan), which is a graphical user interface for R (The R Foundation for Statistical Computing, Vienna, Austria) ${ }^{10}$.

\section{Results}

\section{PATIENTS AND LESION CHARACTERISTICS}

The baseline clinical characteristics of the patients are presented in Table 1. A total of 30 patients $(44.8 \%)$ had CAD, $18(26.9 \%)$ had CVD, 8 (11.9\%) had COPD, and 25 (37.3\%) had CKD. All patients were symptomatic. Fifty patients $(74.6 \%)$ presented with claudication (Rutherford classification 2 or $\left.3^{11}\right), 9$ (13.4\%) with
Table 1. Patient and lower limb characteristics $(\mathrm{N}=67)$.

\begin{tabular}{|c|c|c|}
\hline & $\begin{array}{l}\text { MeantSD } \\
\text { or } \mathbf{N}(\%)\end{array}$ \\
\hline \multicolumn{2}{|l|}{ Age (years) } & $70.3 \pm 12.5$ \\
\hline \multicolumn{2}{|l|}{ Body mass index $\left(\mathrm{kg} / \mathrm{m}^{2}\right)$} & $21.4 \pm 3.2$ \\
\hline \multicolumn{2}{|l|}{ Male } & $50(74.6)$ \\
\hline \multicolumn{2}{|l|}{ Coronary artery disease } & $30(44.8)$ \\
\hline \multicolumn{2}{|l|}{ Cerebrovascular disease } & $18(26.9)$ \\
\hline \multicolumn{2}{|l|}{ Congestive heart failure } & $11(16.4)$ \\
\hline \multicolumn{2}{|l|}{ Hypertension } & $55(82.1)$ \\
\hline \multicolumn{2}{|l|}{ Dyslipidaemia } & $38(56.7)$ \\
\hline \multicolumn{2}{|l|}{ Diabetes } & $25(37.3)$ \\
\hline \multicolumn{2}{|l|}{ Smoking history } & $49(73.1)$ \\
\hline \multicolumn{2}{|c|}{ Chronic obstructive pulmonary disease } & $8(11.9)$ \\
\hline \multicolumn{2}{|c|}{ Chronic kidney disease (eGFR <60 ml/min/1.73 m²) } & $25(37.3)$ \\
\hline \multicolumn{2}{|l|}{ Haemodialysis } & $5(7.5)$ \\
\hline \multicolumn{2}{|l|}{ BUN (mg/dL) } & $17.8 \pm 9.9$ \\
\hline \multicolumn{2}{|l|}{ CRE (mg/dL) } & $1.38 \pm 2.0$ \\
\hline \multicolumn{2}{|l|}{$\mathrm{Hb}(\mathrm{g} / \mathrm{dL})$} & $12.8 \pm 2.1$ \\
\hline \multicolumn{2}{|l|}{$\mathrm{Ht}(\%)$} & $38.6 \pm 5.8$ \\
\hline \multicolumn{2}{|l|}{$\mathrm{LDL}(\mathrm{mg} / \mathrm{dL})$} & $104 \pm 49$ \\
\hline \multicolumn{2}{|l|}{$\mathrm{HDL}(\mathrm{mg} / \mathrm{dL})$} & $49.1 \pm 16$ \\
\hline \multicolumn{2}{|l|}{$\mathrm{HbAlc}(\%)$} & $6.31 \pm 1.3$ \\
\hline \multirow{6}{*}{$\begin{array}{l}\text { Rutherford classification } \\
\text { before treatment }\end{array}$} & 1 & $0(0)$ \\
\hline & 2 & $6(9.0)$ \\
\hline & 3 & $44(65.7)$ \\
\hline & 4 & $9(13.4)$ \\
\hline & 5 & $6(9.0)$ \\
\hline & 6 & $2(3.0)$ \\
\hline \multirow[t]{2}{*}{$\mathrm{ABI}$ before treatment } & Right & $0.46 \pm 0.20$ \\
\hline & Left & $0.40 \pm 0.25$ \\
\hline
\end{tabular}

ABI: ankle-brachial index; BUN: blood urea nitrogen; CRE: creatinine; $\mathrm{Hb}$ : haemoglobin; HDL: high-density lipoprotein; Ht: haematocrit; LDL: low-density lipoprotein

rest pain (Rutherford classification 4), and 8 (12.0\%) with an ulcer (Rutherford classification 5 or 6). The mean preprocedural ankle-brachial index (ABI) was $0.46 \pm 0.20$ on the right side, and $0.40 \pm 0.25$ on the left side.

Lesion characteristics are summarised in Table 2. A total of 56 lesions (83.6\%) were associated with occlusion from the aorta to the iliac artery, and $11(16.4 \%)$ were associated with solitary aortic occlusion. The mean lesion length was $121 \mathrm{~mm}$. Thirtyfour lesions (50.7\%) showed moderate or severe calcification.

\section{INTERVENTIONAL PROCEDURE OF COMPLETE REVASCULARISATION}

Interventional procedures and initial outcomes of complete EVT are summarised in Table 3. The procedural success rate was $94.0 \%$ (63/67). Procedural failures were due to guidewire passage failure in four patients. Complications occurred in three patients 
Table 2. Lesion characteristics.

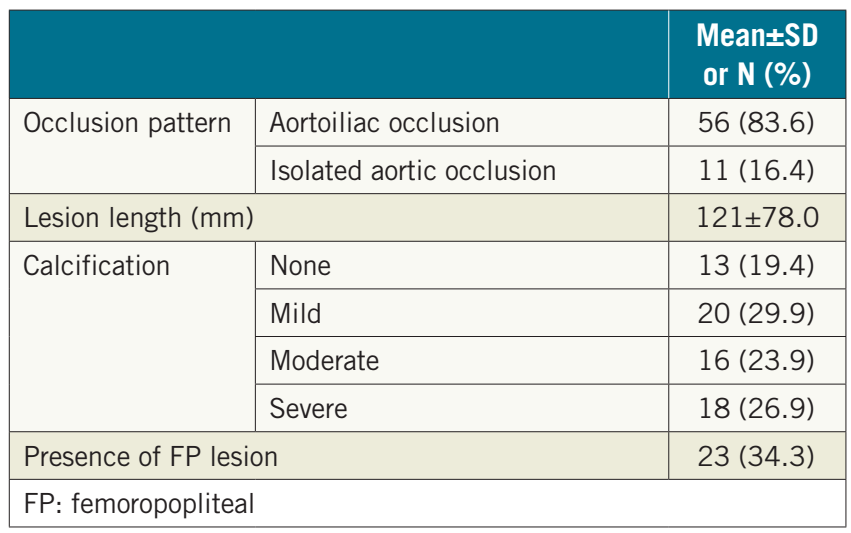

(4.5\%) (stroke, $\mathrm{n}=1$; distal embolism, $\mathrm{n}=1$; access-site haematoma requiring blood transfusion, $\mathrm{n}=1$ ). One case of distal embolism was improved by thromboaspiration only.

Most of the procedures were performed with a bidirectional approach. An intraluminal approach using 0.014-inch and/or 0.018-inch guidewires was performed in more cases (76.1\%) compared with a subintimal approach using a 0.035 -inch guidewire. A total of $88.1 \%$ of the procedures were performed with intravascular ultrasound (IVUS) guidance. The average number of stents per case was $3.2 \pm 1.2$, and $90.0 \%$ of the stents were self-expanding. The kissing stent technique with bare metal stents was performed in 57 cases $(90.5 \%)$. Most of the procedures $(92.5 \%)$ were performed without a distal protection device. Five procedures of distal protection were performed with an occlusion balloon guiding catheter (OPTIMO; Tokai Medical Products, Aichi, Japan).

The ABI and clinical symptoms improved markedly in all patients with successful EVT.

\section{CLINICAL FOLLOW-UP}

Clinical follow-up after successful EVT is summarised in Table 4. Primary and secondary patency rates at 12 months were $90.7 \%$ and $97.7 \%(n=43)$, respectively (Figure 2). During the mean followup period of 17.8 months, either restenosis or re-occlusion was
Table 3. Initial outcome and interventional procedure ( $N=67)$.

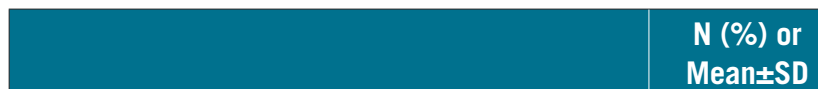

\begin{tabular}{|c|c|}
\hline \multicolumn{2}{|l|}{ Procedure success } \\
\hline Success & $63(94.0)$ \\
\hline Failure & $4(6.0)$ \\
\hline Guidewire crossing failure & 4 \\
\hline Periprocedural complication & $3(4.5)$ \\
\hline Stroke & 1 \\
\hline Distal embolism & 1 \\
\hline Access-site complication & 1 \\
\hline
\end{tabular}

Before and after successful EVT ( $N=63$ )

\begin{tabular}{|c|c|}
\hline \multicolumn{2}{|l|}{ Preprocedural ABI } \\
\hline Right side & $0.46 \pm 0.20$ \\
\hline Left side & $0.41 \pm 0.24$ \\
\hline \multicolumn{2}{|l|}{ Post-procedural ABI } \\
\hline Right side & $0.90 \pm 0.16$ \\
\hline Left side & $0.86 \pm 0.18$ \\
\hline Improvement of the clinical symptoms & $63(100)$ \\
\hline Contrast medium (ml) & $155 \pm 79.6$ \\
\hline Fluoro dose (Gy) & $1.4 \pm 1.3$ \\
\hline \multicolumn{2}{|l|}{ Wiring strategy } \\
\hline Intraluminal & $51(76.1)$ \\
\hline Subintimal & $16(23.9)$ \\
\hline IVUS usage & $59(88.1)$ \\
\hline Number of stents (per case) & $3.2 \pm 1.4$ \\
\hline Total number of stents & 201 \\
\hline Self-expanding stent & $181(90.0)$ \\
\hline Balloon-expandable stent & $20(10.0)$ \\
\hline Kissing stent technique & $57(90.5)$ \\
\hline Distal protection & $5(7.5)$ \\
\hline Occlusion balloon guiding catheter & 5 \\
\hline
\end{tabular}
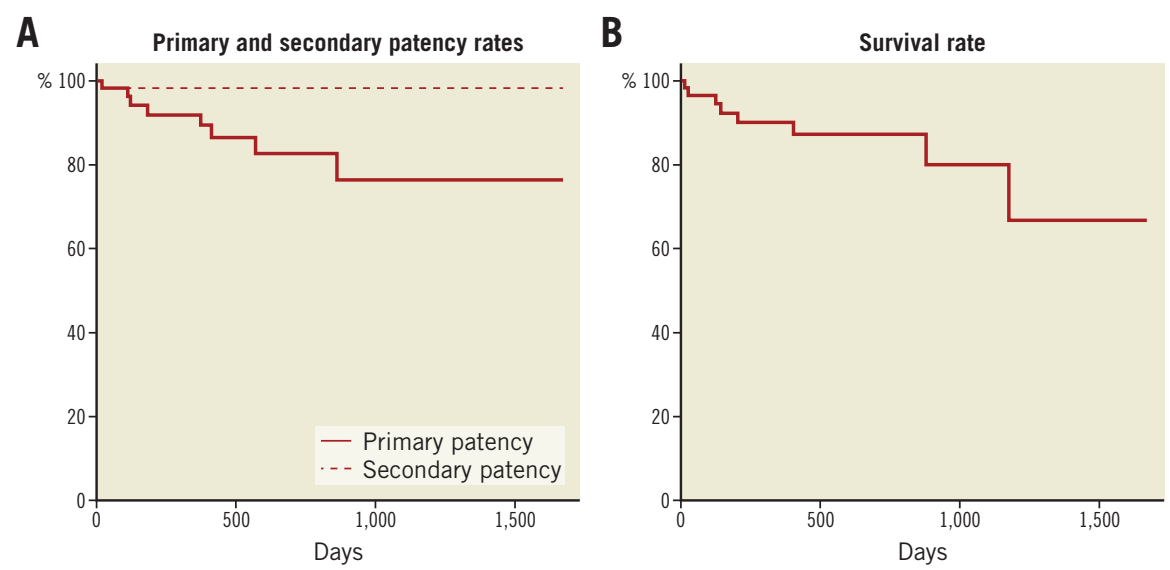

Figure 2. Kaplan-Meier life-table analysis of primary and secondary patency rates. A) After EVT. B) Survival rate. 
Table 4. Clinical follow-up after EVT ( $\mathrm{N}=63)$.

\begin{tabular}{|c|c|}
\hline & $\begin{array}{c}\text { N }(\%) \text { or } \\
\text { Mean } \pm \text { SD }\end{array}$ \\
\hline 12-month primary patency $(\mathrm{N}=43$ ) & 90.7 (39) \\
\hline 12-month secondary patency $(\mathrm{N}=43)$ & $97.7(42)$ \\
\hline Follow-up period (months) & $17.8 \pm 13.9$ \\
\hline Restenosis/re-occlusion & $8(12.7)$ \\
\hline TLR & $7(11.1)$ \\
\hline Balloon angioplasty & 2 \\
\hline Stent implantation & 4 \\
\hline Fogarty catheter embolectomy & 1 \\
\hline Death & $8(12.7)$ \\
\hline Malignancy & 3 \\
\hline Sudden death & 1 \\
\hline Heart failure & 1 \\
\hline Sepsis & 1 \\
\hline Ischaemic colitis & 1 \\
\hline Unknown & 1 \\
\hline Amputation & $1(1.8)$ \\
\hline Toe amputation & 1 \\
\hline Bleeding & $3(4.4)$ \\
\hline Intestinal haemorrhage & 1 \\
\hline Chronic subdural haematoma & 1 \\
\hline Other & 1 \\
\hline
\end{tabular}

observed in eight patients. Among them, seven patients underwent reintervention (additional stent implantation, $n=4$; balloon angioplasty, $n=2$; Fogarty catheter embolectomy, $n=1$ ), five of whom were subsequently relieved of TLR. In one case, intensive medical therapy was maintained, because the patient did not desire reintervention. The incidence of all-cause death was $12.7 \%$ (sudden death, $n=1$; congestive heart failure, $n=1$; malignancy, $n=3$; sepsis, $\mathrm{n}=1$; ischaemic colitis, $\mathrm{n}=1$; unknown cause, $\mathrm{n}=1$ ). There was only one death within 30 days of EVT as a result of sepsis; the patient died 11 days after EVT. The patient presented with severe infectious foot gangrene and was in poor general condition before EVT.

\section{Discussion}

Favourable results of EVT for aortoiliac lesions have been reported $^{1-3}$. Furthermore, in aortoiliac lesions, the primary patency after successful stenting does not differ between TASC II lesion categories $^{3}$.

Recently, EVT of complex lesions has been increasingly performed, yielding high success and low complication rates ${ }^{12}$. Even CTOs are now treated endovascularly with favourable early and long-term results ${ }^{13}$. Hans et $\mathrm{al}^{14}$ reported that aortoiliac stenting can be an alternative to aortobifemoral bypass in TASC C and D lesions. However, EVT for extensive aortoiliac occlusive disease is considered for patients unsuitable for surgical treatment in the present circumstances ${ }^{15,16}$.
CAO is defined as CTO of the infrarenal aorta with or without iliac artery occlusion. Specific ischaemic symptoms of CAO are commonly known as Leriche syndrome ${ }^{4}$. Surgical revascularisation has been the treatment of choice for patients with this disease ${ }^{17}$. Surgical revascularisation for $\mathrm{CAO}$ can be divided roughly into anatomical and extra-anatomical bypass (aortobifemoral and axillobifemoral, respectively). Favourable results of aortobifemoral bypass have been reported ${ }^{18-22}$. However, in older patients, or those at high risk for anatomical bypass, axillofemoral, extra-anatomical bypass is often selected ${ }^{18}$. Although axillofemoral bypass is less invasive, its patency is generally lower than that of aortofemoral bypass ${ }^{17,18,23,24}$. On the other hand, only a small number of single-centre studies have been reported on the outcomes of EVT for $\mathrm{CAO}^{5,6,25}$. We evaluated the safety and efficacy of EVT for CAO using multicentre registry data in this study.

In the present study, we collected data on 73 treated cases of CAO. The average age of the patients was over 70, and many patients had some comorbidities.

In this study, three patients underwent unilateral revascularisation. Two of them with a non-ambulatory status had an ulcer on only one leg. The remaining one had already undergone unilateral limb amputation. Another two patients underwent the hybrid procedure, comprising unilateral endovascular treatment and femorofemoral bypass surgery. The occlusive lesions of the two patients showed severe calcification. It is considered to be a valid decision to shorten the procedural time based on the age and status of the patient, as well as the lesion characteristics.

Complete EVT procedures failed in four cases, all of which were due to guidewire passage failure. In all these cases, the guidewire could not be crossed through the occlusive lesion due to marked calcification. A markedly calcified lesion is still one of the greatest challenges of EVT despite progress in techniques and therapeutic devices.

Next, we would like to consider procedural safety. The periprocedural complication rate was low in this study. There was no arterial rupture or procedure-related death. Another serious complication in aortoiliac intervention is distal embolisation. Only one patient developed minor distal embolisation in this study, although most procedures were performed without distal protection. It should be noted that most of the procedures in this study were performed with IVUS guidance (88.2\%). IVUS images provide much information - on the vessel size, plaque characteristics, location and degree of plaque calcification, and the location of the guidewire in the CTO lesion. The usefulness of IVUS-guided EVT for improving procedural success and post-procedural patency has already been reported ${ }^{26,27}$. Moreover, IVUS usage might contribute to a safe procedure.

In this study, all of the successful EVT cases were treated with bare metal stents, and most cases were treated with the kissing stent technique. The covered endovascular reconstruction of an aortic bifurcation (CERAB) technique ${ }^{28}$ may become one of the useful options. 
Even when EVT is successfully and safely completed, a risk of restenosis remains. In this study, one-year primary and secondary patency rates were $90.7 \%$ and $97.7 \%$, respectively. This result is comparable to past reports of overall aortoiliac lesions ${ }^{3}$ and chronic aortic occlusion ${ }^{6,25}$. In this study, either restenosis or re-occlusion was observed in eight cases (12.7\%) during a mean follow-up period of 17.8 months. Among them, seven patients underwent reintervention, five of whom subsequently showed TLR resolution. Soga et $\mathrm{al}^{3}$ reported that the individual predictors of primary patency in aortoiliac lesions are female sex, diabetes, renal failure, non-use of aspirin, reference vessel diameter $<8.0 \mathrm{~mm}$, and an outflow lesion. In this study, various collected parameters did not show significant differences between the restenosis and non-restenosis groups (Table 5). The statistical power may not have been sufficient.

Table 5. Various parameters between the ISR and non-ISR groups.

\begin{tabular}{|l|c|c|c|}
\hline & ISR (n=8) & $\begin{array}{c}\text { non-ISR } \\
(\mathbf{n = 5 5 )}\end{array}$ & $\boldsymbol{p}$-value \\
\hline Female gender (\%) & 37.5 & 23.6 & 0.328 \\
\hline Age (years) & $68.1 \pm 14.9$ & $69.9 \pm 12.1$ & 0.495 \\
\hline Diabetes (\%) & 25.0 & 41.8 & 0.265 \\
\hline CKD (\%) & 25.0 & 38.2 & 0.432 \\
\hline CLI before treatment & 12.5 & 27.3 & 0.970 \\
\hline Aortoiliac occlusion (\%) & 87.5 & 81.8 & 0.503 \\
\hline Lesion length (mm) & $118 \pm 74$ & $119 \pm 80$ & 0.662 \\
\hline Moderate or severe calcification & 50.0 & 47.3 & 0.805 \\
\hline FP lesion & 25.0 & 32.7 & 0.831 \\
\hline IVUS usage rate & 100 & 87.3 & 0.994 \\
\hline $\begin{array}{l}\text { CKD: chronic kidney disease; CLI: critical limb ischaemia; } \\
\text { FP: femoropopliteal; ISR: in-stent restenosis; IVUS: intravascular } \\
\text { ultrasound }\end{array}$ \\
\hline
\end{tabular}

The incidence of all-cause death was $12.7 \%$ (sudden death, $\mathrm{n}=1$; congestive heart failure, $\mathrm{n}=1$; malignancy, $\mathrm{n}=3$; sepsis, $\mathrm{n}=1$; ischaemic colitis, $n=1$; unknown cause, $n=1$ ). The life prognosis of patients with peripheral artery disease is generally poor ${ }^{17}$, and the indication for revascularisation should be carefully considered.

This is the first report on the clinical outcome of EVT for CAO using multicentre registry data including a relatively large number of patients. More long-term durability of EVT for CAO is expected.

\section{Limitations}

There are some limitations of this study that should be noted. Firstly, this study was a non-randomised, retrospective registry, and decisions on the treatment strategy were not unified in each institution. Secondly, the sample size was small, although this study contains the highest number of cases reported to date. Thirdly, the follow-up period was relatively short. Finally, the racial background of all patients was Japanese, and the results may not be representative if the methods are applied to a broader patient population. Despite these limitations, the results of this study provide important information regarding EVT for CAO.

\section{Conclusions}

In conclusion, EVT for CAO could be performed safely with a high procedural success rate, and the short-term clinical outcome was acceptable despite lesion complexity. The evolution of techniques and materials may contribute to a further increase in the success of such procedures in the future.

\section{Impact on daily practice}

The evidence of clinical outcomes of EVT for CAO is insufficient despite the marked advances in complex EVT over the past few years. This is a first report of multicentre analysis of EVT for CAO, and the clinical outcome was acceptable. Especially in patients who are not candidates for surgery and/ or older patients, EVT for CAO can be an alternative choice.

\section{Acknowledgements}

This article was supported in part by Endovascular Asia (https://endovascularasia.com), a non-profit physician education and research meeting. The authors thank the following physicians for their contribution to and collaboration with this study: Takuo Nakagami, National Hospital Organization Maizuru Medical Center, Maizuru, Japan; Daisuke Naito, Fukuchiyama City Hospital, Fukuchiyama, Japan; Shinichi Takeda, Ijinkai Takeda Hospital, Kyoto, Japan; Yoshifumi Hano, Kyoto Katsura Hospital, Kyoto, Japan; Tetsuo Horimatsu and Machiko Nishimura, Hyogo College of Medicine, Nishinomiya, Japan.

\section{Conflict of interest statement}

The authors have no conflicts of interest to declare.

\section{References}

1. Murphy TP, Ariaratnam NS, Carney WI Jr, Slaiby JM, Soares GM, Kim HM. Aortoiliac insufficiency: long-term experience with stent placement for treatment. Radiology. 2004; 231:243-9.

2. Jongkind V, Akkersdijk GJ, Yeung KK, Wisselink W. A systematic review of endovascular treatment of extensive aortoiliac occlusive disease. J Vasc Surg. 2010;52:1376-83.

3. Soga Y, Iida O, Kawasaki D, Yamauchi Y, Suzuki K, Hirano K, Koshida R, Kamoi D, Tazaki J, Higashitani M, Shintani Y, Yamaoka T, Okazaki S, Suematsu N, Tsuchiya T, Miyashita Y, Shinozaki N, Takahashi H; REAL-AI investigators. Contemporary outcomes after endovascular treatment for aorto-iliac artery disease. Circ J. 2012;76:2697-704.

4. Leriche R, Morel A. The Syndrome of Thrombotic Obliteration of the Aortic Bifurcation. Ann Surg. 1948;127:193-206.

5. Dohi T, Iida O, Okamoto S, Nanto K, Nanto S, Uematsu M. Mid-term clinical outcome following endovascular therapy in 
patients with chronic aortic occlusion. Cardiovasc Interv Ther. 2013;28:327-32.

6. Kim TH, Ko YG, Kim U, Kim JS, Choi D, Hong MK, Jang Y, Shim WH. Outcomes of endovascular treatment of chronic total occlusion of the infrarenal aorta. J Vasc Surg. 2011;53:1542-9.

7. Alkhouli M, Shafi I, Patil P, Bashir R. Percutaneous treatment of chronic distal aortic occlusion: a viable option. JACC Cardiovasc Interv. 2014;7:e185-6.

8. Nadahama T, Kawarada O, Shibata K, Harada K, Noguchi T, Minatoya K, Ogawa H, Yasuda S. Stenting for Juxtarenal Abdominal Aortic Occlusion. JACC Cardiovasc Interv. 2016;9:856-8.

9. Kubota H, Kato T, Nomura T, Keira N, Tatsumi T. Successful endovascular treatment with GuideLiner catheter of chronic aortic occlusion with severe calcification. Cardiovasc Interv Ther. 2017;32:137-41.

10. Kanda Y. Investigation of the freely available easy-to-use software 'EZR' for medical statistics. Bone Marrow Transplant. 2013;48:452-8.

11. Rutherford RB, Baker JD, Ernst C, Johnston KW, Porter JM, Ahn S, Jones DN. Recommended standards for reports dealing with lower extremity ischemia: revised version. J Vasc Surg. 1997;26: 517-38.

12. Leville CD, Kashyap VS, Clair DG, Bena JF, Lyden SP, Greenberg RK, O'Hara PJ, Sarac TP, Ouriel K. Endovascular management of iliac artery occlusions: extending treatment to TransAtlantic Inter-Society Consensus class C and D patients. J Vasc Surg. 2006;33:32-9.

13. Pulli R, Dorigo W, Fargion A, Innocenti AA, Pratesi G, Marek J, Pratesi C. Early and long-term comparison of endovascular treatment of iliac artery occlusions and stenosis. J Vasc Surg. 2011;53:92-8.

14. Hans SS, DeSantis D, Siddiiqui R, Khoury M. Results of endovascular therapy and aortobifemoral grafting for Transatlantic Inter-Society type C and D aortoiliac occlusive disease. Surgery. 2008;144:583-9.

15. European Stroke Organisation, Tendera M, Aboyans V, Bartelink ML, Baumgartner I, Clément D, Collet JP, Cremonesi A, De Carlo M, Erbel R, Fowkes FG, Heras M, Kownator S, Minar E, Ostergren J, Poldermans D, Riambau V, Roffi M, Röther J, Sievert H, van Sambeek M, Zeller T; ESC Committee for Practice Guidelines. ESC Guidelines on the diagnosis and treatment of peripheral artery diseases: Document covering atherosclerotic disease of extracranial carotid and vertebral, mesenteric, renal, upper and lower extremity arteries: the Task Force on the Diagnosis and Treatment of Peripheral Artery Diseases of the European Society of Cardiology (ESC). Eur Heart J. 2011;32:2851-906.

16. Society for Vascular Surgery lower extremity guidelines writing group, Conte MS, Pomposelli FB, Clair DG, Geraghty PJ, McKinsey JF, Mills JL, Moneta GL, Murad MH, Powell RJ,
Reed AB, Schanzer A, Sidawy AN; Society for Vascular Surgery. Society for Vascular Surgery practice guidelines for atherosclerotic occlusive disease of the lower extremities: management of asymptomatic disease and claudication. J Vasc Surg. 2015;61: 2S-41S.

17. Norgren L, Hiatt WR, Dormandy JA, Nehler MR, Harris KA, Fowkes FG; TASC II Working Group. Inter-Society Consensus for the Management of Peripheral Arterial Disease (TASC II). J Vasc Surg. 2007;45:S5-67.

18. Hertzer NR, Bena JF, Karafa MT. A personal experience with direct reconstruction and extra-anatomic bypass for aortoiliofemoral occlusive disease. J Vasc Surg. 2007;45:527-35.

19. Kashyap VS, Pavkov ML, Bena JF, Sarac TP, O'Hara PJ, Lyden SP, Clair DG. The management of severe aortoiliac occlusive disease: endovascular therapy rivals open reconstruction. J Vasc Surg. 2008;48:1451-7.

20. West CA Jr, Johnson LW, Doucet L, Caldito G, Heldman M, Szarvas T, Speirs RD, Carson S. A contemporary experience of open aortic reconstruction in patients with chronic atherosclerotic occlusion of the abdominal aorta. J Vasc Surg. 2010;52:1164-72.

21. Ballotta E, Lorenzetti R, Piatto G, Tolin F, Da Giau G, Toniato A. Reconstructive surgery for complex aortoiliac occlusive disease in young adults. J Vasc Surg. 2012;56:1606-14.

22. Bredahl K, Jensen LP, Schroeder TV, Sillesen H, Nielsen H, Eiberg JP. Mortality and complications after aortic bifurcated bypass procedures for chronic aortoiliac occlusive disease. $J$ Vasc Surg. 2015;62:75-82.

23. Schnelder JR, Golan JF. The role of extraanatomic bypass in the management of bilateral aortoiliac occlusive disease. Semin Vasc Surg. 1994;7:35-44.

24. Martin D, Katz SG. Axillofemoral bypass for aortoiliac occlusive disease. Am J Surg. 2000;180:100-3.

25. Moise MA, Alvarez-Tostado JA, Clair DG, Greenberg RK, Lyden SP, Srivastava SD, Eagleton M, Sarac TS, Kashyap VS. Endovascular management of chronic infrarenal aortic occlusion. J Endovasc Ther. 2009;16:84-92.

26. Kawasaki D, Tsujino T, Fuijii K, Masutani M, Ohyanagi M, Masuyama T. Novel use of ultrasound guidance for recanalization of iliac, femoral, and popliteal arteries. Catheter Cardiovasc Interv. 2008;71:727-33.

27. Kumakura H, Kanai H, Araki Y, Hojo Y, Iwasaki T, Ichikawa S. 15-Year Patency and Life Expectancy After Primary Stenting Guided by Intravascular Ultrasound for Iliac Artery Lesions in Peripheral Arterial Disease. JACC Cardiovasc Interv. 2015;8:1893-901.

28. Goverde PC, Grimme FA, Verbruggen PJ, Reijnen MM. Covered endovascular reconstruction of aortic bifurcation (CERAB) technique: a new approach in treating extensive aortoiliac occlusive disease. J Cardiovasc Surg. 2013;54:383-7. 